\title{
Transformation of phosphorus fractions in paddy soil amended with pig manure
}

\author{
Y. Yin, C. H. Liang* \\ Department of Soil and Environment, Shenyang Agricultural University, Shenyang 110866, China. "Corresponding author: \\ liang110161@163.com
}

\begin{abstract}
This paper examines phosphorus forms following application of organic fertilizer. Dynamic changes in the phosphorus fraction content were simulated by the waterlogged incubation method. This study was carried out using comparison tests between sterilized and non-sterilized treatments to analyze the effect of organic fertilizer on phosphorus form transformation. The experimental results showed that fertilization of paddy soil could significantly increase the content of the phosphorus fraction $(p<0.05)$. Furthermore, the organic phosphorus content increased during incubation. The levels of organic phosphorus in the non-sterilized treatments were higher than in the sterilized treatments. However, the variation of the inorganic phosphorus content was contradictory. A significant correlation $(\mathrm{r}=-0.484, p \leq 0.01)$ was observed between O-P and highly resistant organic phosphorus, as well as among Al-P, Ca-P, moderately labile organic phosphorus and moderately resistant organic phosphorus. Therefore, it is concluded that applying organic fertilizer can increase the content of the phosphorus fractions of paddy soil. With microorganisms present, Al-P and Ca-P can be transformed into moderately labile organic phosphorus and moderately resistant organic phosphorus, and O-P can be transformed into highly resistant organic phosphorus.
\end{abstract}

Keywords: paddy soil, organic fertilizer, phosphorus forms, transformation

\section{Introduction}

Phosphorus (P) management is of agronomic and environmental significance (Hountin et al, 2000). Losses of $\mathrm{P}$ are usually related to soil $\mathrm{P}$ concentration and ameliorated by $\mathrm{P}$ addition via fertilizers and manures (McDowell and Sharpley, 2001). In the literature, fertilizer recommendations and research efforts typically adopt the nutrient balance technique and fertilizer effect regression equations to calculate the optimum $\mathrm{P}$ application rates for maximum crop yield and economic return (Liu et al, 2007b). However, such approaches do not take the transformation of different $\mathrm{P}$ forms into consideration and, thus, are not able to accurately evaluate the potential environmental risk from $\mathrm{P}$ fertilization in agricultural ecosystems. Therefore, it is imperative to investigate the effect of $\mathrm{P}$ application via mineral fertilizers or manure on the transformation of $\mathrm{P}$ forms and the risk of $\mathrm{P}$ loss from agricultural ecosystems in order to accurately assess the environmental impact of $\mathrm{P}$ fertilization. 
Continuous $\mathrm{P}$ fertilization may have a long-term effect on the content of $\mathrm{P}$ fractions in the soil in addition to its yield-increasing effect (Wang et al, 2010). The transformation of different $P$ forms in the soil is usually determined by complex interactions of biotic and abiotic factors. Adsorption and dissolution are some of the abiotic factors controlling nutrient transfer between non-living pools and soluble forms, whereas biotic factors, including microbial activity, change organic $\mathrm{P}$ into inorganic $\mathrm{P}$, and vice versa (Azeez and Averbeke, 2010). Most studies have been focused on the transformation of organic $\mathrm{P}$ fractions into inorganic $\mathrm{P}$ fractions through the process of mineralization.

Manure contains a significant proportion of organic $\mathrm{P}$ fractions and inorganic $\mathrm{P}$ forms. In manure, organic P represents less than $30 \%$ of the total $\mathrm{P}$ content (Romanya and Rovira, 2009). Different types of $\mathrm{P}$ fractions may differ remarkably in mobility, bioavailability and chemical behavior and can be transformed under certain conditions (Jalali and Ranjbar, 2010). Consequently, the contents of different $\mathrm{P}$ fractions could indicate distinct bioavailability to crops and potentially have negative impacts on the environment. Some laboratory incubation studies have shown that the addition of manure could considerably increase the soil organic P fraction content (Reddy et al, 2000).

Soil $\mathrm{P}$ fraction transformation has been a major focus of research in soil chemistry (Yang et al, 2012). The relationship between organic and inorganic $\mathrm{P}$ forms has been broadly discussed in several studies. For example, larger fractions of $\mathrm{P}$ available to agricultural crops were shown to be maintained due to a higher rate of cycling for organic $\mathrm{P}$ than for inorganic $\mathrm{P}$ (Xavier et al, 2009). The Ca-P, Fe-P, Al-P and organic $\mathrm{P}$ fractions are considered to be relatively active depending on the actual properties of the soil (Jalali and Ranjbar, 2010). In addition, it has been reported that $\mathrm{P}$ application in excess to what is taken up by the crop remained in the soil, and its transformation into organic or inorganic forms depends on the management practices of other nutrients and the inherent soil conditions (Singh, 2007). Information on the chemical forms of $\mathrm{P}$ is fundamental to understanding $\mathrm{P}$ dynamics and interactions in paddy soils, which is necessary for management of $\mathrm{P}$. However, little is known about the cycling of $\mathrm{P}$ in soil, including the fate of $\mathrm{P}$ in manure applied to paddy soil. Therefore, this paper aims to evaluate the effect of manure application on the transformation of the $\mathrm{P}$ fractions in paddy soil.

\section{Materials and Methods}

\subsection{Soil sampling and sample analysis}

Surface $(0-20 \mathrm{~cm})$ soils were sampled from the Liaoning province in northeast China $\left(41.84^{\circ} \mathrm{N}\right.$, $123.57^{\circ} \mathrm{E}$ ). Air-dried soil was sieved through a $2-\mathrm{mm}$ mesh prior to analysis. Sample $\mathrm{pH}$ was determined in soil/manure: water suspensions (1: 2.5/10 ratios) with a glass electrode ( $\mathrm{Lu}, 2000$; NY 525-2002). Samples were analyzed for total carbon (TC) and total nitrogen (TN) using a Liqui TC/TN elementar of Germany (supplied by Hangzhou Hanze Instruments Incorporated). The available $\mathrm{P}$ in soils was extracted with $0.5 \mathrm{M} \mathrm{NaHCO}(\mathrm{pH}$ 8.5) and determined spectrophotometrically as blue molybdate-phosphate complexes under partial reduction with ascorbic acid (Olsen, 1965). The total phosphorus (TP) of soils was determined by digestion with the $\mathrm{NaHCO}_{3}-\mathrm{NaOH}$ method (Bao, 1981). Manure-available $\mathrm{P}$ and TP were determined according to the methods of NY/T 300 1995 and NY 525-2002, respectively.

Inorganic phosphorus was fractionated according to the sequential extraction procedure of Jackson (Bao, 1981). Organic phosphorus was fractionated using the Bowman-Cole method (Bowman, 1976). The main properties are summarized in Table 1. 
Table 1. Main properties of the soil and manure studied.

\begin{tabular}{lll}
\hline Property & Soil content & Manure content \\
\hline $\mathrm{pH}(1: 2.5 / 10$ soil/manure-water) & 6.33 & 8.28 \\
$\mathrm{TC}\left(\mathrm{g} \cdot \mathrm{kg}^{-1}\right)$ & 5.85 & 219.90 \\
$\mathrm{TN}\left(\mathrm{g} \cdot \mathrm{kg}^{-1}\right)$ & 1.04 & 24.53 \\
$\mathrm{TP}\left(\mathrm{g} \cdot \mathrm{kg}^{-1}\right)$ & 0.47 & 27.3 \\
Available phosphorus $\left(\mathrm{mg} \cdot \mathrm{kg}^{-1}\right)$ & 30.46 & 2164.40 \\
Inorganic phosphorus fractions $\left(\mathrm{mg} \cdot \mathrm{kg}^{-1}\right)$ & & \\
Al-P & 35.36 & 3926.76 \\
Fe-P & 156.68 & 5589.69 \\
O-P & 150.42 & 3532.76 \\
Ca-P & 56.08 & 1803.16 \\
Organic phosphorus fractions $\left(\mathrm{mg} \cdot \mathrm{kg}^{-1}\right)$ & & \\
Labile $\mathrm{P}_{\mathrm{o}}$ & 22.00 & 3444.04 \\
Moderately labile $\mathrm{P}_{\mathrm{o}}$ & 54.68 & 9359.52 \\
Moderately resistant $\mathrm{P}_{\mathrm{o}}$ & 25.75 & 1565.43 \\
Highly resistant $\mathrm{P}_{\mathrm{o}}$ & 13.22 & 1688.69 \\
\hline
\end{tabular}

\subsection{Treatments of soil samples}

A laboratory waterlogged incubation experiment was established at the experimental station of Shenyang Agricultural University in autumn 2011 to study the effect of manure on the phosphorus fraction transformation. Portions of soil and manure samples were sterilized by autoclaving at $121{ }^{\circ} \mathrm{C}$ and 1.5 atmospheres for one hour. Phosphorus fractions of the samples were studied in sterile and non-sterile conditions after applying pig manure.

Triplicate $30.0000 \mathrm{~g}$ soil samples were weighed out with high precision and transferred into $100 \mathrm{ml}$ sterile plastic containers (Sterile)/ plastic containers (Unsterile) with different amounts of manure. Five initial manure amounts $(0.1500 \mathrm{~g}, 0.3000 \mathrm{~g}, 0.7500 \mathrm{~g}, 1.5000 \mathrm{~g}$ and $2.2500 \mathrm{~g})$ were used. After thorough mixing, the samples were maintained under a 3-cm-layer of sterile or non-sterile distilled water. For sterile treatments, two drops of chloroform were added to each container to prevent bacterial growth. The waterlogged soils were then incubated up to $30 \mathrm{~d}$ in a dark cupboard at $25^{\circ} \mathrm{C}$ in 3 replicates. Aliquots were removed after $0,6,12,18$, 24 and $30 \mathrm{~d}$ for phosphorus fractionation. The sterility of batches was checked for soil incubated under sterile conditions prior to the initiation of the experiment.

\subsection{Phosphorus fractionation}

Organic phosphorus (Po) fractionation

The incubated soil samples were air-dried and strained through 2-mm sieves. For all samples, $\mathrm{NaHCO}_{3}$ extracted $\mathrm{P}_{\mathrm{i}}$ and $\mathrm{P}_{\mathrm{o}}$ were determined (Olsen, 1954; Watanabe and Olsen, 1965). The extracted $P_{0}$ was determined as the increase in Pi after perchloric acid digestion. Triplicate $2-\mathrm{g}$ samples of air-dried incubated soil were extracted with $100 \mathrm{ml} 1.0 \mathrm{M} \mathrm{H}_{2} \mathrm{SO}_{4}$ for $3 \mathrm{~h}$, and the $\mathrm{P}_{\mathrm{i}}$ and $\mathrm{P}_{\mathrm{o}}$ levels of the filtrates were determined. 
The acid-treated soil samples were transferred quantitatively to the filter paper and washed with 2 to $3 \mathrm{ml}$ ethanol. After drying, the soil samples were extracted in $100 \mathrm{ml} 0.5 \mathrm{M} \mathrm{NaOH}$ for $6 \mathrm{~h}$. Both the $\mathrm{P}_{\mathrm{i}}$ and Po levels were determined in all samples after centrifugation. The alkali extracts were acidified with concentrated $\mathrm{HCl}$ to $\mathrm{pH} 1.0-1.5$ in order to precipitate humic-acid P. After centrifugation, the concentrations of $\mathrm{P}_{\mathrm{i}}$ and $\mathrm{P}_{\mathrm{o}}$ were determined in the acid solution.

Inorganic phosphorus $\left(\mathrm{P}_{\mathrm{i}}\right)$ fractionation

The following inorganic $\mathrm{P}$ fractions of the incubated soil samples were measured in sequence: (1) Solution $\mathrm{P}$, by shaking $1.00 \mathrm{~g}$ sample of sieved $<0.15 \mathrm{~mm}$ soil in $50 \mathrm{ml} 1.0 \mathrm{M} \mathrm{NH}_{4} \mathrm{Cl}$ for half an hour, centrifuging and filtering; (2) Al-P, by shaking the residue from (1) in $50 \mathrm{ml} 0.5 \mathrm{M} \mathrm{NH}_{4} \mathrm{~F}$ for $1 \mathrm{~h}$, centrifuging, and filtering, and then measuring $\mathrm{P}$ in the filtrate; (3) Fe$\mathrm{P}$, by shaking the residue from (2) in $50 \mathrm{ml} 0.1 \mathrm{M}$ $\mathrm{NaOH}$ for $2 \mathrm{~h}$, incubating for $16 \mathrm{~h}$, shaking for $2 \mathrm{~h}$, centrifuging, and filtering and then measuring $\mathrm{P}$ in the filtrate after acidifying with $1.5 \mathrm{ml}$ concentrated $\mathrm{H}_{2} \mathrm{SO}_{4}$ followed by filtering; (4) O-P, by agitating the residue from (3) in $40 \mathrm{ml} 0.3 \mathrm{M}$ sodium citrate and $1.0 \mathrm{~g} \mathrm{Na}_{2} \mathrm{~S}_{2} \mathrm{O}_{4} \cdot 2 \mathrm{H}_{2} \mathrm{O}$ for $15 \mathrm{~min}\left(80 \sim 90{ }^{\circ} \mathrm{C}\right)$, shaking in $10 \mathrm{ml} 0.5 \mathrm{M} \mathrm{NaOH}$ for $10 \mathrm{~min}$, cooling, and centrifuging and then digesting $10 \mathrm{ml}$ of the filtrate in $10 \mathrm{ml}$ of a 1:2:7 mixture concentrated $\mathrm{H}_{2} \mathrm{SO}_{4}, \mathrm{HClO}_{4}$ and $\mathrm{HNO}_{3}$, refluxing, and cooling until the residue turned white, and then determining $\mathrm{P}$ in the digest; and (5) Ca-P, by shaking the residue from (4) in $50 \mathrm{ml}$ $0.25 \mathrm{M} \mathrm{H}_{2} \mathrm{SO}_{4}$ for $1 \mathrm{~h}$, centrifuging, and filtering, and then measuring $\mathrm{P}$ in the filtrate.

\subsection{Statistical analysis}

Data treatment and statistical analysis were performed using the SPSS 18.0 Program. Treatment effects were assessed by two-way ANOVA. Differences were considered statistically significant at $p<0.05$ (LSD). The effect of manure treatments in sterile and nonsterile conditions was analyzed separately. Pearson's $\mathrm{r}$ correlation $(p \leq 0.01$ and $p \leq 0.05)$ was calculated and used to test the transformation relationships between organic phosphorus and inorganic phosphorus.

\section{Results and Discussion}

\subsection{Organic phosphorus $\left(P_{o}\right)$ fractions}

The proportions of the different $\mathrm{P}$ fractions were significantly affected by the type of soil and the particular treatment. The contents of all $\mathrm{P}_{\mathrm{o}}$ fractions obtained from the sequential extraction scheme (Bowman and Cole, 1978) after manure applications are shown in Table 2. In general, the content of the $\mathrm{P}_{\mathrm{o}}$ forms were as follows: moderately labile $\mathrm{P}_{0}(\mathrm{MLOP})>$ moderately resistant $\mathrm{P}_{0}(\mathrm{MROP})>$ labile $\mathrm{P}_{0}(\mathrm{LOP})>$ highly resistant $\mathrm{P}_{\mathrm{o}}(\mathrm{HROP})$. There were gradual, yet statistically insignificant, increases in soil $\mathrm{P}_{\mathrm{o}}$, relative to day 0 , up to day 24 . A significantly higher soil $\mathrm{P}_{\mathrm{o}}$ was recorded on day 24 , and the values decreased thereafter.

A wide range of $\mathrm{P}$ concentrations in the soil extract was identified within each of the Po fractions during incubation (Table 2). In general, the magnitude of the increase was $33 \%, 18 \%, 27 \%$ and $51 \%$, for LOP, MLOP, MROP and HROP, respectively. In manure, LOP accounted for $11 \%$ of the total P, MLOP for $30 \%$, MROP for $6 \%$ and HROP for $5 \%$. However, even though the HROP fraction was the lowest in manure, followed by MROP, these fractions cause significant imbalances in the soil fractions after incubation. As a result, for all studied soils, the $\mathrm{P}$ contents in different $\mathrm{P}_{\mathrm{o}}$ fractions increased during soil incubation, which suggests the existence of an organic phosphorus synthesis mechanism linked to manure application. A similar result was also found by Singh et al. (2007).

Analysis of variance indicated that significantly $(p<0.05)$ greater $\mathrm{P}_{\mathrm{o}}$ concentrations in each fraction were extracted with manure than without manure (Table 2). Additionally, the concentration of the $\mathrm{P}_{\text {o }}$ fractions increased with manure application for both 
Table 2. Concentrations of the Po fractions during the soil incubation

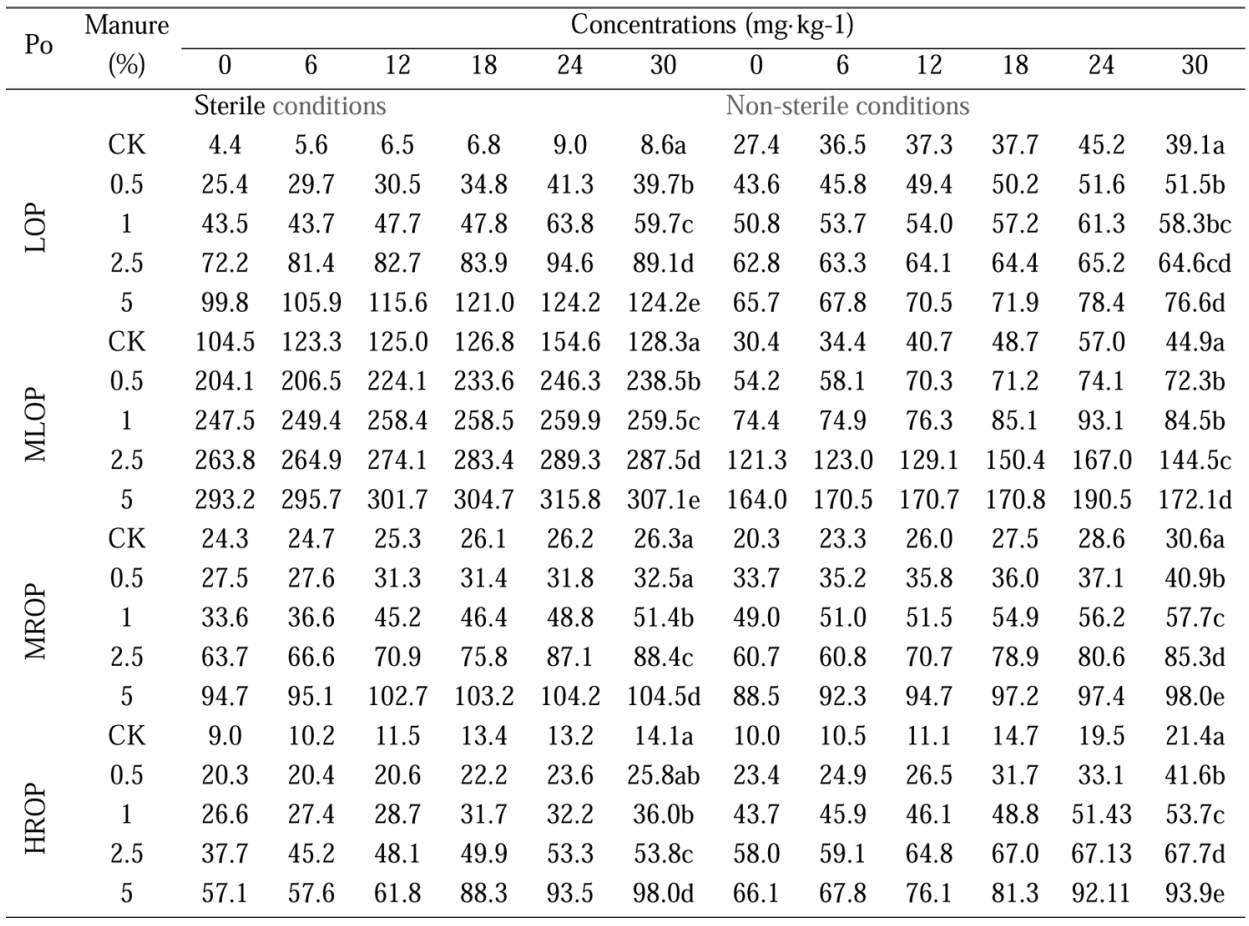

*The same letter refers to insignificant differences among manure applications $(n=5)$ based on the LSD Test $(p \leq 0.05)$.

sterile and non-sterile conditions, which indicated the extent to which Po fractions increased or were affected by manure applications. Long-term manure application had a more positive impact on the accumulation of soil Po fractions, which is consistent with the results obtained by Pizzeghello et al. (2011) and Agbenin \& Goladi (1997).

\subsection{Inorganic phosphorus $(P$, fractions}

The $\mathrm{P}$ contents in different $\mathrm{P}_{\mathrm{i}}$ fractions of the soils are given in Table 3. There were gradual, yet significantly different $(p<0.05)$ decreases in soil Al-P and O-P relative to day 0 during the the incubation. The $P$ concentration within each of the $\mathrm{P}_{\mathrm{i}}$ fractions of the soil also varied widely during incubation (Table 3 ). In general, the magnitude of the decrease was $24 \%, 27 \%$ and $6 \%$, for Al-P, O-P and Ca-P, respectively, and the increase was $7 \%$ for $\mathrm{Fe}-\mathrm{P}$. It was observed that the $\mathrm{P}$ concentrations of Al-P and O-P decreased during the soil incubation, which indicates the existence of a decomposition mechanism of Al-P and O-P upon manure application. The opposite trend occurred for Fe-P, suggesting a Fe-P synthesis mechanism upon manure application. A significantly higher soil Fe-P was recorded at day 18 under sterile conditions and day 6 under non-sterile conditions, and the values decreased significantly afterwards. Furthermore, the highest $\mathrm{P}$ concentrations of Al-P, O-P and Ca-P were observed on day 0 during incubation. 
Table 3. Concentrations of Pi fractions during soil incubation

\begin{tabular}{|c|c|c|c|c|c|c|c|c|c|c|c|c|c|}
\hline \multirow{2}{*}{$\mathrm{P}_{0}$} & \multirow{2}{*}{$\begin{array}{c}\text { Manure } \\
(\%)\end{array}$} & \multicolumn{12}{|c|}{ Concentrations $\left(\mathrm{mg} \cdot \mathrm{kg}^{-1}\right)$} \\
\hline & & 0 & 6 & 12 & 18 & 24 & 30 & 0 & 6 & 12 & 18 & 24 & 30 \\
\hline & \multicolumn{4}{|c|}{ Sterile conditions } & \multicolumn{9}{|c|}{ Non-sterile conditions } \\
\hline \multirow{5}{*}{$\frac{9}{1}$} & CK & 31.1 & 28.6 & 25.1 & 24.8 & 23.0 & $23.0 \mathrm{a}$ & 53.1 & 52.3 & 51.7 & 42.2 & 38.5 & $31.1 \mathrm{a}$ \\
\hline & 0.5 & 53.1 & 35.6 & 34.7 & 32.7 & 32.4 & $31.7 \mathrm{a}$ & 90.22 & 82.6 & 81.8 & 78.8 & 77.1 & $76.2 \mathrm{~b}$ \\
\hline & 1 & 55.4 & 54.6 & 44.5 & 39.7 & 39.3 & $38.5 b$ & 110.6 & 107.7 & 103.8 & 100.0 & 98.5 & $95.4 \mathrm{c}$ \\
\hline & 2.5 & 106.5 & 101.7 & 98.6 & 93.4 & 91.5 & $88.0 \mathrm{c}$ & 174.9 & 166.2 & 161.4 & 155.2 & 150.5 & $146.5 \mathrm{~d}$ \\
\hline & 5 & 150.8 & 146.3 & 139.4 & 127.9 & 113.4 & $110.1 d$ & 295.9 & 291.1 & 286.3 & 278.2 & 275.6 & $270.8 \mathrm{e}$ \\
\hline \multirow{5}{*}{$\begin{array}{l}\bar{d} \\
\text { du․ }\end{array}$} & CK & 137.4 & 138.7 & 144.8 & 150.1 & 144.8 & $144.7 \mathrm{a}$ & 147.3 & 182.8 & 182.2 & 176.3 & 171.9 & 159.3a \\
\hline & 0.5 & 147.3 & 149.4 & 155. 6 & 165.5 & 164.2 & $162.2 b$ & 187.2 & 236.0 & 230.0 & 225.7 & 217.0 & 193.5ab \\
\hline & 1 & 170.0 & 171.2 & 171.3 & 178.3 & 177.5 & $176.4 \mathrm{c}$ & 240.0 & 266.4 & 265.3 & 262.6 & 259.5 & $255.9 \mathrm{~b}$ \\
\hline & 2.5 & 229.9 & 240.9 & 256.3 & 260.4 & 259.2 & $253.9 \mathrm{~d}$ & 330.0 & 373.3 & 351.1 & 349.3 & 348.8 & $345.8 \mathrm{c}$ \\
\hline & 5 & 262.3 & 263.9 & 275.7 & 282.5 & 276.4 & $275.6 \mathrm{e}$ & 462.8 & 568.7 & 541.2 & 522.4 & 514.9 & $506.3 \mathrm{~d}$ \\
\hline \multirow{5}{*}{ ó } & $\mathrm{CK}$ & 85.6 & 84.1 & 71.6 & 65.1 & 54.9 & $53.2 \mathrm{a}$ & 75.6 & 70.4 & 68.0 & 63.6 & 48.8 & $43.3 \mathrm{a}$ \\
\hline & 0.5 & 88.0 & 86.2 & 74.7 & 70.3 & 61.6 & $60.4 a$ & 109.2 & 98.3 & 96.7 & 96.0 & 94.0 & $90.8 \mathrm{~b}$ \\
\hline & 1 & 97.6 & 97.2 & 88.2 & 70.5 & 64.6 & $62.4 \mathrm{a}$ & 124.1 & 121.2 & 119.0 & 117.3 & 115.3 & $110.6 \mathrm{~b}$ \\
\hline & 2.5 & 189.5 & 182.8 & 169.7 & 169.5 & 117.4 & $108.0 \mathrm{~b}$ & 257.8 & 245.5 & 240.8 & 235.8 & 208.6 & $189.8 \mathrm{c}$ \\
\hline & 5 & 269.3 & 268.7 & 264.1 & 242.0 & 226.5 & $217.7 \mathrm{c}$ & 438.8 & 423.2 & 415.3 & 414.4 & 403.7 & $399.3 d$ \\
\hline \multirow{5}{*}{ U. } & CK & 53.6 & 51.1 & 51.0 & 47.1 & 49.6 & 51.1a & 69.2 & 60.8 & 55.6 & 53.6 & 63.7 & $66.3 a$ \\
\hline & 0.5 & 55.6 & 55.4 & 54.4 & 50.9 & 52.0 & $53.8 \mathrm{a}$ & 88.1 & 80.4 & 76.3 & 72.5 & 80.6 & $83.6 \mathrm{~b}$ \\
\hline & 1 & 67.8 & 63.7 & 61.6 & 60.7 & 60.7 & $60.7 \mathrm{~b}$ & 97.9 & 95.6 & 91.1 & 89.0 & 90.9 & $92.4 \mathrm{c}$ \\
\hline & 2.5 & 83.6 & 82.7 & 79.8 & 71.2 & 75.3 & $77.8 \mathrm{c}$ & 115.2 & 101.0 & 100.4 & 99.9 & 103.8 & $113.3 \mathrm{~d}$ \\
\hline & 5 & 103.8 & 102.2 & 97.9 & 84.4 & 89.7 & $93.4 \mathrm{~d}$ & 177.6 & 164.6 & 155.3 & 149.8 & 154.4 & $165.6 \mathrm{e}$ \\
\hline
\end{tabular}

* The same letters refer to non-significant differences among manure applications $(n=5)$ based on the LSD Test $(p \leq 0.05)$.

The concentration of Ca-P decreased under sterile conditions, whereas it increased under non-sterile conditions.

The concentrations of the $\mathrm{P}_{\mathrm{i}}$ fractions increased significantly $(p<0.05)$ with increasing application of manure. This finding suggested that the addition of manure resulted in increased $P_{i}$ concentrations in the four fractions. No significant difference was identified between the O-P contents resulting from manure applications of $0.5 \%$ and $1 \%$ in non-sterile incubation conditions due to O-P transformation by microbes. In general, the contents of the $\mathrm{P}_{\mathrm{i}}$ fractions in non-sterile conditions were higher than those in sterile conditions. These results are similar to the results observed by Sharpley et al. (2004), in that concentrations of $\mathrm{P}_{\mathrm{i}}$ were significantly greater in soils receiving manure compared to untreated soils.

\subsection{Transformation of phosphorus fractions}

In all treatments, the contents of the $\mathrm{P}$ fractions increased with the addition of manure. In general, manure application has appreciable and dynamic impacts on the chemical fractions of $\mathrm{P}$ because $\mathrm{P}$ from manure gradually turn into available forms over time (Halajnia et al., 2009). Although there is consistently more inorganic (63 to $92 \%$ ) than organic (5 to $25 \%$ ) $\mathrm{P}$ in manure, the relative distribution of $\mathrm{P}$ within the inorganic and organic fractions are highly variable (Sharpley and Moyer, 2000). Previous experimental results (Sharpley et al., 2004) revealed a relative increase in $\mathrm{P}_{\mathrm{i}}$ forms compared with $\mathrm{Po}$ in soils to which manure had been applied. However, there was a change in the extractability and abundance of dominant forms of $\mathrm{P}$ in soils with long-term application of manure. 
However, differences have been identified between the contents of the $\mathrm{P}$ fractions in soil and the contents of the $\mathrm{P}$ fractions in manure, as well as between the contents of the $\mathrm{P}$ fractions in the sterile and nonsterile conditions. Hence, this indicates the presence of a transformation mechanism among $\mathrm{P}$ fractions after addition of manure. The correlation between manure application and variations of phosphorus fractions relative to control soils was analyzed in the present study. The correlation coefficients are shown in Figures 1, 2, 3.

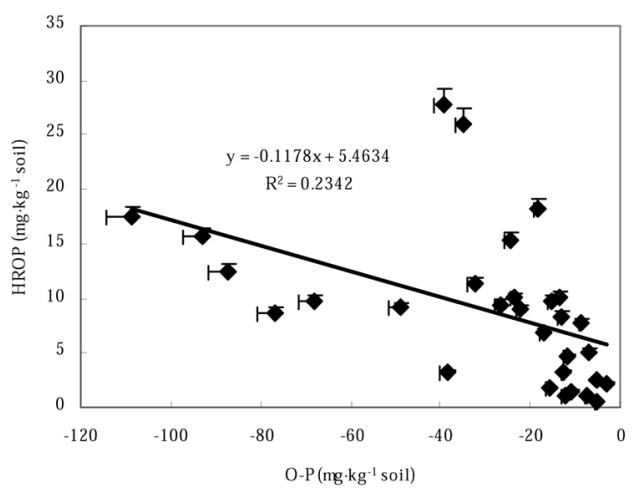

Figure 1. Correlations among the concentrations (relative to control soils) of highly resistant $\mathrm{P}_{\mathrm{o}}$ and $\mathrm{O}-\mathrm{P}$ in the soil studied. Pearson's $\mathrm{r}$ correlation was used to test the relationships between the response variables. Asterisks denote significance ${ }^{*} p \leq 0.05$, ** $p \leq 0.01)$. The data obtained for unsterile soil are included in the analysis.

Simple correlation coefficients showed that manure application was positively correlated with variation of all $\mathrm{P}$ fractions. These results suggest that the application of manure could increase the content of the soil P fractions. Similar results were also found by Liu et al. (2007b).

In the present study, negative significant relationships were observed between O-P and HROP $\left(\mathrm{r}=-0.484^{* *}\right)$ in

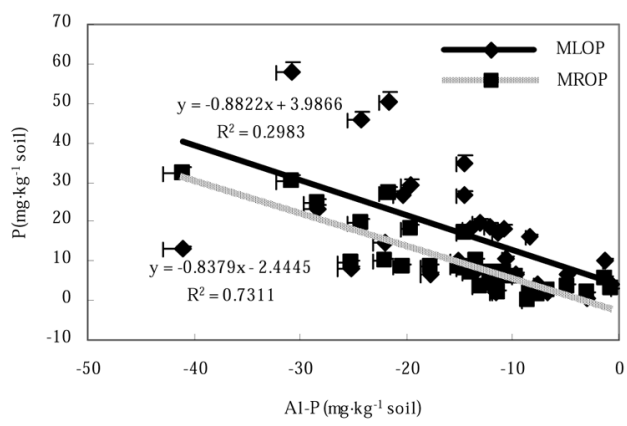

Figure 2. Correlations among the concentrations (relative to control soils) of moderately labile Po (MLOP) and Al-P and among those of moderately resistant Po (MROP) and Al-P in the soil studied. Pearson's $r$ correlation was used to test the relationships between the response variables. Asterisks denote significance $(* p \leq 0.05, * * p \leq 0.01)$. The data obtained for unsterile soil are included in the analysis.

the non-sterile condition. In fact, MLOP and MROP were highly correlated with Al-P $\left(\mathrm{r}=-0.546^{* *}\right.$ and $\mathrm{r}=-$ $0.855^{* *}$, respectively $)$ as well as with $\mathrm{Ca}-\mathrm{P}\left(\mathrm{r}=-0.535^{* *}\right.$ and $\mathrm{r}=-0.403^{*}$ ) in the non-sterile condition. However, these results were not found in the sterile condition. The results suggest the existence of transformation mechanisms of Al-P and Ca-P into MLOP and MROP, and O-P into HROP, by means of potentially complex microbial biochemical reactions after the addition of manure. These results are in agreement with those of Pavinato et al. (2009) and Reddy et al. (2000).

In general, manure application reduces the ability of the soil to fix P (Azeez and Averbeke, 2010). However, the solubility of Po appears to be greater. Overall, $\mathrm{P}_{\mathrm{i}}$ is the dominant fraction in all soils, however, the relative proportion of $\mathrm{P}_{\mathrm{i}}$ to $\mathrm{P}_{\mathrm{o}}$ decreases as the rates of manure application increase (McDowell and Sharpley, 2001). The transformation among $\mathrm{P}$ fractions has been broadly discussed in several studies. For example, manure application has been shown to promote the transformation of $\mathrm{P}_{\mathrm{i}}$ into more stable $\mathrm{P}$ forms 
(Xavier et al, 2009). When fertilizer $\mathrm{P}$ is supplied together with manure, the MLOP and MROP forms seem to represent the main P sources in the soil (Reddy et al, 2000). In addition, a previous study showed that a large proportion of $\mathrm{P}$ was added as manure was adsorbed and remained in moderately labile fractions (Pavinato et al, 2009). KCl-P, which is considered as an indication of the soluble forms in calcareous soil, was shown to be transformed to more stable fractions (HCl-P and $\mathrm{NaOH}-\mathrm{P}$ ) after manure application (Jalali and Ranjbar, 2010). In addition, an accumulation of MLOP in silt loam soil has been shown with manure application (Hountin et al, 2000). Finally, more Ca-P, as a labile pool, was shown to accumulate due to the transformation from other fractions after long-term continuous inorganic fertilizer application, which improved soil P availability (Wang et al, 2010).

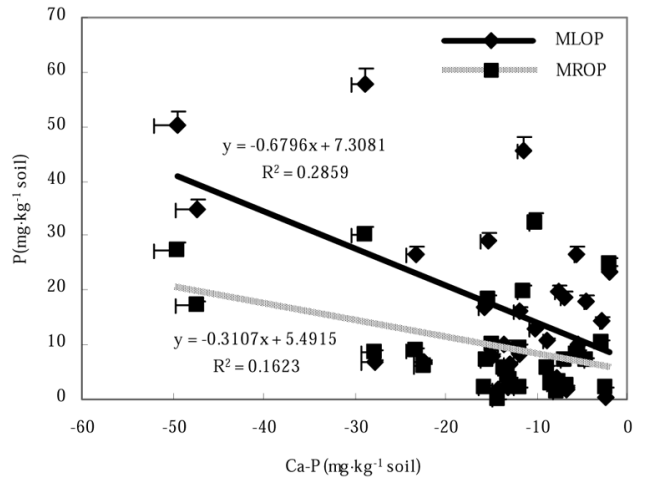

Figure 3. Correlations among the concentrations (relative to control soils) of moderately labile Po (MLOP) and Ca-P and among those of moderately resistant Po (MROP) and Ca-P in the soil studied. Pearson's $r$ correlation was used to test the relationships between the response variables. Asterisks denote significance $\left.{ }^{*} p \leq 0.05,{ }^{* *} p \leq 0.01\right)$. The data obtained for unsterile soil are included in the analysis.

\section{Conclusions}

The results of this study indicate that the addition of manure to paddy soil increased the contents of the phosphorus fractions during the incubation, concomitant with an increase in phosphorus transformations.

The concentrations of labile $\mathrm{P}_{0}$, moderately labile $\mathrm{P}_{\mathrm{o}}$, moderately resistant $\mathrm{P}_{\mathrm{o}}$, highly resistant $\mathrm{Po}, \mathrm{Al}-\mathrm{P}, \mathrm{Fe}-\mathrm{P}$, $\mathrm{O}-\mathrm{P}$ and $\mathrm{Ca}-\mathrm{P}$ in the soil increased with the increase of manure application rates. Correlation among different soil P fractions was also found, which can be used to explore the effect of manure on phosphorus forms and their risk to the environment.

The experimental results also highlighted the role of manure applications in promoting phosphorus transformation. As expected, the phosphorus forms transformed from Al-P and Ca-P into moderately labile Po and moderately resistant Po and from O-P into highly resistant Po after pig manure application. These findings could have important implications for agricultural systems and environmental sciences. Finally, it is necessary to study the effect of fertilization on phosphorus transformation in more detail in future work.

\section{Acknowledgments}

This research was supported by the Chinese Research Program of the Department of Agriculture of Liaoning Province.

\section{References}

Agbenin, J.O., Goladi, J.T. 1997. Carbon, nitrogen and phosphorus dynamics under continuous cultivation as influenced by farmyard manure and inorganic fertilizers in the savanna of northern Nigeria. Agriculture, Ecosystems and Environment. 63, 17-24. 
Amelung, W., Rodionov, A., Urusevslaja, I.S., Haumaier, L., Zech, W. 2001. Forms of organic phosphorus in zonal steppe soils of Russia assessed by 31P NMR. Geoderma. 109, 335-350.

Anderson, D. L., Tuovinen, O. H., Faber, A., Ostrokowski, I. 1995. Use of soil amendments to reduce soluble phosphorus in dairy soils. Ecological Engineering. 5, 229-246.

Azeez, J.O., Averbeke, W.V. 2010. Fate of manure phosphorus in a weathered sandy clay loam soil amended with three animal manures. Bioresource Technology. 101, 6584-6588.

Bao, S. D. 1981. Soil agriculturalization analysis. China Agriculture Press, Beijing.

Bowman, R. A., Cole, C. V. 1978. An exploratory method for fractionation of organic phosphorus from grassland soils. Soil Science. 125, 95-101.

Daroub, S. H., Gerakis, A., Ritchie, J. T., Friesen, D. K., Ryan, J.2003. Development of a soil-plant phosphorus simulation model for calcareous and weathered tropical soils. Agricultural Systems. $76,1157-1181$

Halajnia, A., Haghnia, G. H., Fotovat, A., Khorasani, R. 2009. Phosphorus fractions in calcareous soils amended with $\mathrm{P}$ fertilizer and cattle manure. Geoderma. 150, 209-213.

He, Z.L., Zhu, J. 1998. Microbial utilization and transformation of phosphate adsorbed by variable charge minerals. Soil Biol. Biochem. 30, $917-$ 923.

Hountin, J.A., Karam, A., Couillard, D., Cescas, M.P. 2000. Use of a fractionation procedure to assess the potential for $\mathrm{P}$ movement in a soil profile after 14 years of liquid pig manure fertilization. Agriculture, Ecosystems and Environment. $78,77-84$
Jalali, M., Ranjbar, F. 2010. Aging effects on phosphorus transformation rate and fractionation in some calcareous soils. Geoderma. 155, 101106.

Kostyanovsky, K.I., Evanylo, G.K., Lasley, K.K., Daniels, W.L., Shang, C. 2011. Leaching potential and forms of phosphorus in deep row applied biosolids underlying hybrid poplar. Ecological Engineering. 37, 1765-1771.

Liu, J. L., Liao, W. H., Zhang, Z. X., Zhang, H. T., Wang, X. J., Meng, N. 2007. Effect of phosphate fertilizer and manure on crop yield, soil $\mathrm{P}$ accumulation, and the environmental risk assessment. Agricultural Sciences in China. 6, 1107-1114.

Lu, R. K (Ed). 2000. Methods of soil and agrochemistry analysis. Chinese Agricultural Science and Technology Press, Beijing.

McDowell, R. W., Sharpley, A. N. 2001. Soil phosphorus fractions in solution: influence of fertilizer and manure, filtration and method of determination. Chemosphere. , 45, 737-748.

Pavinato, P. S., Merlin, A., Rosolem, C. A. 2009. Phosphorus fractions in Brazilian Cerrado soils as affected by tillage. Soil \& Tillage Research. $105,149-155$.

Pheav, S., Bell, R.W., White, P.F., Kirk, G.J.D. 2003. Fate of applied fertilizer phosphorus in a highly weathered sandy soil under lowland rice cropping and its residual effect. Field Crops Research. 81, $1-16$.

Pizzeghello, D., Berti, A., Nardi, S., Morari, F. 2011. Phosphorus forms and P-sorption properties in three alkaline soils after long-term mineral and manure applications in north-eastern Italy. Agriculture, Ecosystems and Environment. 141, 58-66. 
Reddy, D.D., Rao, A.S., Rupa, T.R. 2000. Effects of continupus use of cattle manure and fertilizer phosphorus on crop yields and soil organic phosphorus in a Vertisol. Bioresource Technology. $75,113-118$.

Romanyà, J., Rovira, P. 2009. Organic and inorganic $P$ reserves in rain-fed and irrigated calcareous soils under long-term organic and conventional agriculture. Geoderma. 151, 378-386.

Sharpley, A. N., McDowell, R. W., Kleinman, P. J. A. 2004. Amounts, forms, and solubility of phosphorus in soils receiving manure. Soil Science Society of America. 68, 2048-2057.

Sharpley, A., Moyer, B. 2000. Phosphorus forms in manure and compost and their release during simulated rainfall. J. Environ. Qual. 29, $1462-$ 1469.

Sharpley, A.N. 1995. Soil phosphorus dynamics: agronomic and environmental impacts. Ecological Engineering. 5, 261-279.
Singh, M., Reddy, K.S., Singh, V.P., Rupa, T.R. 2007. Phosphorus availability to rice (Oriza sativa L.) wheat (Triticum estivum L.) in a Vertisol after eight years of inorganic and organic fertilizer additions. Bioresource Technology. 98, 1474-1481.

Wang, J., Liu, W.Z., Mu, H.F., Dang, T.H. 2010. Inorganic phosphorus fractions and phosphorus availability in a calcareous soil receiving 21-year superphosphate application. Pedosphere. 20, 304310.

Xavier, F.A.S., Oliveira, T.S., Andrade, F.V., Mendonca, E.S. 2009. Phosphorus fractionation in a sandy soil under organic agriculture in Northeastern Brazil. Geoderma. 151, 417-423.

Yang, J.C., Wang, Z.G., Zhou, J., Jiang, H.M., Zhang, J.F., Pan, P., Han, Z., Lu, C., Li, L.L., Ge, C.L. 2012. Inorganic phosphorus fractionation and its translocation dynamics in a low-P soil. Journal of Environmental Radioactivity. 112, 64-69. 